\title{
EL DESPLAZAMIENTO DE TRABAJADORES EN EL MARCO DE UNA PRESTACIÓN TRANSNACIONAL DE SERVICIOS: HACIA UN MARCO NORMATIVO EUROPEO MÁS SEGURO, JUSTO Y ESPECIALIZADO
}

\author{
NURIA MARCHAL ESCALONA ${ }^{1}$ \\ Universidad de Granada \\ nmarchal@ugr.es
}

\section{Resumen}

La Directiva 96/71/CE fue diseñada por el legislador de la Unión Europea para garantizar a los trabajadores desplazados un «núcleo duro» de derechos y evitar así situaciones de competencia desleal. Sin embargo, a pesar del impacto que causó su adopción, ha sido, en gran medida, una norma que a la postre ha dado lugar a comportamientos fraudulentos y abusivos en detrimento de los derechos de los trabajadores. Esta situación motivó la aprobación tanto de la Directiva 2014/67/CE como de la reciente Directiva 2018/957/UE, y justifica la presentación de la propuesta de

1 Profesora titular de Derecho Internacional Privado de la Universidad de Granada. Trabajo realizado en el marco del Proyecto I+D, «Movilidad internacional de personas. El impacto jurídico-social en España y en la UE de la adquisición de la nacionalidad española por la población inmigrante» (DER2016-75573R DER2016-78139-R). 
directiva (2017) elaborada en el sector del transporte por carretera, que contiene normas que pretenden corregir los déficits de la Directiva 96/71/CE. El presente estudio tiene por objeto analizar las soluciones adoptadas por el nuevo derecho de la Unión Europea en este ámbito a fin de lograr un régimen más justo, seguro y especializado para la movilidad de trabajadores desplazados en el marco de una prestación de servicios transnacional.

\title{
Palabras clave
}

Trabajadores desplazados; dumping social; prestación transnacional de servicios; Directiva 96/71/CE; Directiva 2014/67/UE; Directiva 2018/957/UE.

\section{THE POSTING OF WORKERS IN THE FRAMEWORK OF A PROVISION OF A SERVICES: TOWARDS A SAFER, FAIRER AND SPECIALIZCED EUROPEAN FRAMEWORK}

\begin{abstract}
Directive 96/71/EC was designed by the European legislator to guarantee post workers a "hard core" of rights and thus to avoid situations of unfair competition. However, despite the impact that its adoption has caused, it has been, to a large extent, a rule that in the end has led to fraudulent and abusive behaviors to the detriment of workers' rights. The situation caused the approval of both Directive 2014/67/EU and the recent Directive 2018/957/EU, and justifies the presentation of the Proposal for a Directive (2017) prepared in the road transport sector, rules that aim to correct the deficits of Directive 96/71/EC. The aim of this study is to analyze the solutions adopted by the new European law in this area in order to achieve a fairer, safer and specialized regime for the mobility framework of the provision of services.
\end{abstract}

\section{Keywords}

The posting of workers; transnational service provision; social dumping; Directive 96/71/EC; Directive 2014/67/UE; Directive 2018/957/UE.

\section{LE DÉPLACEMENT DES TRAVAILLEURS DANS LE CADRE D'UNE PRESTATION TRANSNATIONALE DES SERVICES: VERS UN CADRE RÉGLEMENTAIRE EUROPÉEN PLUS SÛR, PLUS JUSTE ET PLUS SPÉCIALISÉ}

\section{Résumé}

La Directive 96/71/CE a été conçue par le législateur européen pour garantir aux travailleurs déplacés un «noyau dur» de droits et éviter ainsi des situations de 
concurrence déloyale. Cependant, malgré l'impact de son adoption, elle a, dans une large mesure, été une règle qui a finalement entrainé des comportements frauduleux et abusifs au détriment des droits des travailleurs. Cette situation a conduit à l'approbation de la Directive 2014/67/UE et de la récente Directive 2018/957/UE, et justifie la présentation de la proposition de directive (2017) préparée dans le secteur des transports routiers, qui contient des règles visant à corriger les déficits de la Directive 96/71/CE. Le but de cette étude est d'analyser les solutions adoptées par la nouvelle loi européenne dans ce domaine afin de mettre en place un régime plus équitable, plus sûr et plus spécialisé pour la mobilité des travailleurs déplacés dans le cadre de la fourniture de services transnationaux.

\section{Mots clés}

Travailleurs déplacés; prestation de services transnationale; dumping social; Directive 96/71/CE; Directive 2014/67/UE; Directive 2018/957/UE. 


\section{SUMARIO}

I. INTRODUCCIÓN. II. EL DERECHO DE LA UNIÓN EUROPEA DE LOS DESPLAZAMIENTOS DE TRABAJADORES EN EL MARCO DE UNA PRESTACIÓN TRANSNACIONAL DE SERVICIOS: 1. El proceso de armonización indirecta: la labor del Tribunal de Justicia de la Unión Europea. 2. De la Directiva 96/71 a la Directiva 2014/67. III. LA ADAPTACIÓN AL NUEVO DERECHO DE LA UNIÓN EUROPEA DE DEPLAZAMIENTO TEMPORAL DE TRABAJADORES EN EL MARCO DE UNA PRESTACIÓN TRANSNACIONAL DE SERVICIOS: ESPECIAL REFERENCIA AL SISTEMA ESPAÑOL: 1. Introducción. 2. Las obligaciones dirigidas a las autoridades encargadas de aplicar el nuevo derecho UE. 3. Las obligaciones de información, cooperación administrativa, comparecencia y presentación de documentos. IV. HACIA UN MARCO NORMATIVO MÁS SEGURO, JUSTO Y ESPECIALIZADO EN LA UNIÓN EUROPEA PARA LOS TRABAJADORES DESPLAZADOS: 1. Introducción. 2. Nueva categoría jurídica: del trabajador temporalmente desplazado en el marco de una prestación transnacional de servicios al trabajador desplazado de larga duración. 3. La protección laboral del trabajador desplazado en la Directiva 2018/957: 3.1. Las garantías laborales de los trabajadores desplazados. 3.2. Del salario mínimo al principio de «igualdad salarial». 4. Coordinación, cooperación, transparencia, corresponsabilidad y seguridad jurídica contra el abuso y fraude empresarial. 5. La piedra de toque del nuevo derecho de Europa: el desplazamiento de los trabajadores del sector de transporte por carretera. V. CONCLUSIONES. BIBLIOGRAFía.

\section{INTRODUCCIÓN}

Más de veinte años después de la adopción de la Directiva 96/71/CE sobre el desplazamiento de trabajadores efectuado en el marco de una prestación de servicios (en adelante Directiva 96/71) , $^{2}$ con la que el legislador pretendía

2 DOCE L 18, de 21 de enero de 1997, p. 1. Hay que tener presente que el régimen jurídico de un trabajador desplazado resultará, en ocasiones, de la combinación de la lex contractus [ex art 8 del Reglamento (CE) núm. 593/2008 del Parlamento Europeo y del Consejo de 17 de junio de 2008 sobre ley aplicable a las obligaciones contractuales, DOCE núm. L 177, de 4 de julio de 2008 (en adelante, Reglamento Roma I)] más las condiciones laborales exigidas por el Estado de acogida (ex art. 3 Directiva 96/71), mientras que, en otros casos, dependerá solo y exclusivamente de lo dispuesto en la lex contractus. Una cuestión 
garantizar a tales trabajadores la aplicación de ciertas condiciones de trabajo y empleo establecidas en el Estado de acogida ${ }^{3}$ - siempre que fueran más favorables que las previstas en la ley que rige el contrato (ex art. 3.5 de la Directiva 96/71) — y evitar así el denominado dumping social ${ }^{4}$, sus disposiciones han sido objeto de una nueva reforma.

En concreto, dicho proceso comenzó el 8 de marzo de 2016 cuando la Comisión presentó la propuesta de modificación de la Directiva 96/71 —en adelante propuesta de directiva de 2016- (Kramer, 2016: 1-13; Risak, 2016: 1; Guamán Hernández, 2016: 113-126). El objetivo de la misma era avanzar hacia un mercado laboral más justo. El proceso concluyó con la adopción de la Directiva 2018/957/UE del Parlamento Europeo y del Consejo de 28 de junio de 2018, que modifica la Directiva 96/71 sobre el desplazamiento de trabajadores efectuado en el marco de una prestación de servicios (en adelante, Directiva 2018/9575). Con la Directiva 2018/957, el legislador de la Unión Europea (en adelante UE) pretende elevar la protección de los trabajadores desplazados en el marco de una prestación de servicios y luchar de forma efectiva contra el abuso $y$ fraude detectado en dichos desplazamientos ${ }^{6}$, sin que ello suponga un grave

que dependerá de si las disposiciones vigentes en la ley del Estado de acogida resultan ser o no más favorables que las establecidas en la lex contractus.Davies (1997: 751-602); Däubler (1997: 613-618); Rebhahn (1999: 173-179); Eichenhofer (1996: 55-82); Nadalet (2008: 44); Palao Moreno (1997: 377-380); Gutiérrez-Solar Calvo (2000); Carrascosa y Rodríguez-Piñero (1993: 382-407); Moreau (1996: 889-908). Dicha Directiva fue incorporada al ordenamiento jurídico español en virtud de la Ley 45/1999, de 29 de noviembre, sobre el desplazamiento de trabajadores en el marco de una prestación de servicios transnacional (BOE 286, 30 de noviembre de 1999, p. 41231). Para un análisis de la misma, véase Palao Moreno (2000:43-62). Todas las fuentes electrónicas utilizadas en el presente trabajo han sido recuperadas el 15 de enero de 2019.

3 Art. 3.1. Las disposiciones de este precepto han sido calificadas de normas materiales imperativas, de orden público, no sujetas al control de proporcionalidad (Quiñones Escámez, 2012: 448).

4 Para un concepto de dicho término, véase Martín Belintxon (2016: 662).

5 DOUE núm. L 173, 9 de julio de 2018, p. 16. Los Estados deberán incorporar sus disposiciones a más tardar el 30 de julio de 2020. Hasta esa fecha, la Directiva 96/71 seguirá siendo aplicable en su redacción anterior a las modificaciones introducidas por la presente directiva.

6 La directiva no afectará en modo alguno al ejercicio de los derechos fundamentales reconocidos en los Estados miembros y a escala de la Unión, incluyendo el derecho o la libertad de huelga o de emprender otras acciones contempladas en los sistemas de relaciones laborales específicos de los Estados miembros, de conformidad con la legislación o las prácticas nacionales. Tampoco afecta al derecho a negociar, concluir 
perjuicio para las empresas que desplazan a tales trabajadores ${ }^{7}$. Este último objetivo era también compartido por la Directiva 2014/67/UE del Parlamento Europeo y del Consejo, de 15 de mayo de 2014, relativa a la garantía de cumplimiento de la Directiva 96/71/CE sobre el desplazamiento de trabajadores efectuado en el marco de una prestación de servicios, por la que se modifica el Reglamento (UE) núm. 1024/2012 relativo a la cooperación administrativa a través del Sistema de Información del Mercado Interior (Reglamento IMI) ${ }^{8}$ —en adelante Directiva 2014/67(Páramo Montero, 2015: 52-70). Esta directiva fue transpuesta a nuestro ordenamiento en virtud del Real Decreto Ley 9/2017, de 26 de mayo, por el que se incorporaron al ordenamiento jurídico español diversas directivas de la Unión Europea en los ámbitos financiero, mercantil y sanitario9 (Velázquez Fernández, 2017: 95-108).

Igualmente, la Directiva 2018/957 evidencia los problemas prácticos y jurídicos que plantea la aplicación de la Directiva 96/71 en el sector del transporte internacional por carretera (considerando 15) ${ }^{10}$. De hecho, consciente

y hacer cumplir convenios colectivos o llevar a cabo acciones colectivas conforme a la legislación o las prácticas nacionales (art. 1).

7 La base jurídica de dicha directiva se fundamenta en el art. 56 y en el art. 3 en relación con el art. 9 del Tratado del funcionamiento de la Unión Europea (en adelante TFUE) —DOUE núm. C 326, de 26 de octubre de 2012, p. 0001—. Precisamente, Hungría (asunto C-620/18) y Polonia (asunto C-626/18) han presentado un recurso de anulación contra la directiva, entre otras razones por no haber sido adoptada sobre la base jurídica adecuada (DO 2018, L 173, p. 16). Según estos, habida cuenta de su finalidad y de su contenido, dicha directiva se dirige exclusivamente, o al menos con carácter principal, a la protección de los trabajadores, por lo que el legislador de la Unión debería haberla adoptado sobre la base del art. 153 TFUE. Sin embargo, el Tribunal de Justicia de la Unión Europea (en adelante, TJUE) ha sido tajante al señalar que el personal de una empresa establecida en un Estado miembro, que es enviado temporalmente a otro Estado miembro para realizar prestaciones de servicios, no pretende en modo alguno acceder al mercado laboral de este segundo Estado, ya que vuelve a su país de origen o de residencia después de haber concluido su misión (por ejemplo, la Sentencia de 27 de marzo de 1990, Rush Portuguesa, 113/89, EU:C:1994:310; Sentencia de 9 de agosto de 1994 , Vander Elst, 43/93, EU:C:1994:310). Por lo que, las disposiciones relativas a la libre circulación de trabajadores no resultan de aplicación en tales casos (por ejemplo, la Sentencia de 24 enero de 2002, Portugaia, 164/99, EU:C:2002:40).

8 DOUE núm. L 159, de 28 de mayo de 2014, p. 11. Sobre la relevancia del sistema IMI como modelo de cooperación administrativa internacional entre Estados miembros véase Pelkmans y Correia de Brito (2012: 106-107).

9 BOE 126, 27 de mayo de 2017, p. 42820. Correc. error. BOE 136, 8 de junio de 2017, p. 46673.

10 En concreto, el art. 3 de la Directiva 2018/957 establece que será de aplicación a partir de la fecha de aplicación de un acto legislativo que modifique la Directiva 2006/22/ 
de la problemática existente en este ámbito, la Comisión presentó, el 31 de mayo de 2017, la Propuesta de Directiva del Parlamento Europeo y del Consejo por la que se modifica la Directiva 2006/22/CE en lo relativo a los requisitos de control del cumplimiento, y en la que se fijan normas específicas con respecto a la Directiva 96/71 y la Directiva 2014/67 para el desplazamiento de los conductores en el sector del transporte por carretera ${ }^{11}$.

El presente trabajo se ocupará de analizar el nuevo régimen normativo que el legislador de la Unión Europea pretende instaurar para los trabajadores desplazados en el marco de una prestación transnacional de servicios y, en particular, para los trabajadores en el sector del transporte. A tales efectos, será preciso examinar cómo se ha ido avanzando en este ámbito para ofrecer una protección más efectiva a este tipo de trabajadores. Particularmente, nos centraremos en la incorporación del nuevo derecho de la UE en los sistemas estatales y, especialmente, en las novedades incorporadas a la Ley 45/1999 tras la transposición al ordenamiento jurídico español de la Directiva 2014/67.

Para los fines del presente estudio, hay que tener en cuenta que, según los arts. 1 y 2 de la Directiva 96/71, no todos los trabajadores desplazados en el marco de una prestación transnacional de servicios pueden gozar de la protección que el derecho de la UE les dispensa (Rodière, 1998: 9-18; Gárate Castro, 2013). Esta confiere protección solo a aquellos trabajadores trasladados de forma temporal a otros Estados miembros, por cuenta y dirección de su empresa, en el marco de un contrato de prestación de servicios, de un grupo de empresas o de un contrato de puesta a disposición transnacional.

\section{EL DERECHO DE LA UNIÓN EUROPEA DE LOS DESPLAZAMIENTOS DE TRABAJADORES EN EL MARCO DE UNA PRESTACIÓN TRANSNACIONAL DE SERVICIOS}

\section{EL PROCESO DE ARMONIZACIÓN INDIRECTA: LA LABOR DEL TRIBUNAL DE JUSTICIA DE LA UNIÓN EUROPEA}

El desplazamiento transnacional de trabajadores en el marco de una prestación de servicios implica el traslado de unos trabajadores que desempeñan su trabajo en un Estado miembro de la UE (Estado de origen) a otro país (Estado

CE en lo relativo a los requisitos de control del cumplimiento y que establezca normas específicas con respecto a la Directiva 96/71 y la Directiva 2014/67 para el desplazamiento de conductores en el sector del transporte por carretera.

11 COM (2017) 278 final, 3-5-2017. 
de acogida), para realizar un determinado servicio por un concreto periodo de tiempo. La cuestión que surge de inmediato es determinar qué normas del Estado de acogida deberán observar las empresas prestadoras de servicios que deseen desplazar a sus trabajadores a otro Estado, esto es, qué condiciones laborales habrán de cumplir. Este interrogante alcanza todo su sentido en el ámbito europeo, sobre todo si tenemos en cuenta que supeditar la prestación de servicios a la observancia de todos los requisitos exigidos para el establecimiento puede privar de eficacia a las disposiciones del TFUE destinadas a garantizar la libre prestación de servicios, tal y como ha admitido el propio Tribunal de Justicia de la Unión Europea (en adelante TJUE) en diversas decisiones.

De hecho, hasta 1996, fecha en la que se aprobó la Directiva 96/71, el TJUE fue el encargado de concretar qué normas estatales del Estado de acogida podían romper con la uniformidad de las condiciones del mercado y, por tanto, representaban serios obstáculos al comercio intracomunitario. El resultado de esta valoración fue la armonización de esta materia al margen de la actuación del legislador de la UE a través de diversas decisiones judiciales (por ejemplo, los asuntos Webb, Seco, Rush Portuguesa y Vander Elst ${ }^{12}$ ). La aprobación de la Directiva 96/71 parecía, pues, el final del papel armonizador desempeñado hasta entonces por el TJUE al enumerar los obstáculos de carácter jurídico-laboral (art. 3) que podían imponer y limitar la libre prestación de servicios de una empresa establecida en un Estado miembro (Marchal Escalona, 2002: 815-816). No obstante, la realidad fue bien distinta ${ }^{13}$. De hecho, son múltiples las ocasiones en las que, con posterioridad a la Directiva 96/71, ha sido precisa la intervención del TJUE, como así se evidenció en los casos Climatec, Arblade, Mazolleni, Finalarte, Portugaia, Wolff, Comisión/República Federal de Alemania, Dos Santos

12 Sentencia de 17 de diciembre de 1981, Webb, 279/80, EU:C:1981:314; Sentencia de 3 de febrero de 1982, Seco, 62 y 63/81, EU:C:1982:3; Sentencia de 27 de marzo de 1990, Rush Portuguesa, 113/89, EU:C:1994:310; Sentencia de 9 de agosto de 1994, Vander Elst, 43/93, EU:C:1994:310.

13 De hecho, el 9 de enero de 2018 se presentó una nueva petición de decisión prejudicial planteada por el Verwaltungsgerichtshof(Austria), en la que se cuestiona lo siguiente: «¿Está comprendida en el ámbito de aplicación de la Directiva 96/71, en particular de su artículo $1.3^{\circ}$ a), la prestación de servicios tales como el suministro de comida y bebida a los pasajeros, el servicio a bordo o los servicios de limpieza por parte de los trabajadores de una empresa de servicios establecida en el Estado miembro de origen (Hungría) en cumplimiento de un contrato con una empresa ferroviaria establecida en el Estado miembro de acogida (Austria), cuando dichos servicios son prestados en trenes internacionales que también circulan por el Estado miembro de acogida?» (DO C123, de 9 de abril de 2018, p. 10). 
Palhota, Tevfik Isbir, Prostejov, De Clercq y Sähköalojen Ammattiliitto ry ${ }^{14}$. Una jurisprudencia en la que se hace patente la inclinación del TJUE por leer e interpretar los derechos sociales de los trabajadores desplazados a la luz de las exigencias económicas y mercantiles (por ejemplo, los casos Bundesdruckerei y Rüffer $)^{15}$. Aunque, afortunadamente, dicha línea parece, al menos momentáneamente, haber sido abandonada, según se deriva de la sentencia RegioPost GmbH dictada por el TJUE el 17 de noviembre de 2015 al admitir la «legitimad y operatividad» de las exigencias sociales establecidas en el Estado de acogida en las contrataciones públicas ${ }^{16}$ (Marchal Escalona, 2016: 1-18).

\section{DE LA DIRECTIVA 96/71 A LA DIRECTIVA 2014/67}

De lo anterior, resulta evidente que el dispositivo de protección del trabajador desplazado diseñado por el legislador de la UE a través de la Directiva 96/71 era claramente insuficiente. La falta de conceptos claros y precisos a la hora de definir ciertos términos y condiciones de aplicación de la Directiva 96/71 dificultaba en gran medida la aplicación efectiva de las garantías que esta incorpora (Fotinopoulou Basurko, 2017: 258-262). Esta indeterminación coadyuvó, sin duda alguna, a la proliferación de abusos y comportamientos

14 Sentencia de 28 de marzo de 1996, Climatec, 272/94, EU:C:1996:147; Sentencia de 23 de noviembre de 1999, Arblade, 369/96 y 376/96, EU:C:1999:575; Sentencia de 15 de marzo de 2001, Mazzoleni, 165/98, EU:C:2007:809; Sentencia de 25 octubre 2001, Finalarte, 49/98, 50/98, 52/98 a 54/98 y 68/98 a 71/98, EU:C:2001:564; Sentencia de 24 enero de 2002, Portugaia, 164/99, EU:C:2002:40; Sentencia de 12 de octubre de 2004, Wolff, 60/03, EU:C:2004:610; Sentencia de 14 de abril de 2005, Comisión/República Federal de Alemania, 341/02, EU:C:2005:220; Sentencia de 18 de julio de 2007, Comisión/República Federal de Alemania 490/04, EU:C:2007:430; Sentencia de 7 de octubre de 2010, Dos Santos Palhota, 515/08, EU:C:2010:589; Sentencia de 7 noviembre de 2013, Tevfik Isbir, 522/12, EU:C:2013:711; Sentencia de 19 de junio de 2014, Prostejov, 53/13 y 80/13, EU:C:2014:2011; Sentencia de 3 de diciembre de 2014, De Clercq, 315/13, EU:C:2014:2408; Sentencia de 12 de febrero de 2015, Sähköalojen Ammattiliitto ry, 396/13, EU:C:2015:86. Algunos de estos pronunciamientos no han estado exentos de polémica, como así sucedió con las sentencias de 11 de diciembre de 2007 (Viking, 438/05, EU:C:2007:772) y de 18 de diciembre de 2007 (Laval, 341/05, EU:C:2007:809).

15 Sentencia de 18 septiembre de 2014, Bundesdruckerei, 549/13, EU:C:2014:2235; Sentencia de 3 de abril de 2008, Rüffer, 346-06 EU:C:2008:189. Para un análisis de dicha orientación, véase Gómez Muñoz (2016: 1-42).

16 Sentencia de 17 de noviembre de 2015, Regio Post GmbH \& Co.KG, 115/14, EU:C: 2015:760. 
fraudulentos ${ }^{17}$, así como a la creación de empresas ficticias letter box companies (Muller, 2014: 306-321; Sørensen, 2015: 85-118; Llobera Vila, 2018: 53656). Este escenario justifica por qué el legislador de la UE adoptó en la Directiva 2014/67 un marco jurídico más seguro con medidas capaces de garantizar de forma efectiva la protección de los trabajadores desplazados. A tales efectos, la Directiva 2014/67 introduce a escala europea criterios comunes y uniformes para que las autoridades competentes de los distintos Estados miembros puedan determinar cuándo existe un auténtico desplazamiento transnacional de trabajadores en el marco de una prestación de servicios, cuándo el desplazamiento puede ser calificado de temporal (art. 4) ${ }^{18}$. De la misma manera, para mejorar, implementar y garantizar la efectiva aplicación de lo dispuesto en la Directiva 96/71, la Directiva 2014/67 consideró necesario mejorar el acceso a la información sobre las condiciones de empleo (art. 5 de la Directiva 2014/67) a las que se refiere el art. 3 de la Directiva 96/71 ${ }^{19}$ (Gil Pérez, 2017: 173-188; López Rubia, 2017: 305-322), fomentar la cooperación entre las autoridades de los diferentes Estados miembros (arts. 6 a 8 de la Directiva 2014/67), aumentar la efectividad y eficiencia de las inspecciones de trabajo (art 10 de la Directiva 2014/67), concretar qué formalidades administrativas y medidas de control exigidas por la ley del Estado de acogida son exigibles y

17 Según consta en el Informe Eurofound titulado Exploring the Fraudulent Contracting of Work in the European Union, Publications Office of the European Union (Luxemburgo, 2016). Disponible en: https://bit.ly/2gopkfL. Un ejemplo de este tipo de conductas lo encontramos en las sentencias de Cass. Crim. n. ${ }^{\circ} 11-88420$, de 11 de marzo de 2014, EasyJet Airline Company Ltd y Cass. Crim. n. ${ }^{\circ} 12-81461$, de 11 de marzo de 2014, Vueling Airlines, en las que se calificó como fraude de ley el comportamiento de sendas compañías aéreas que ejercían su actividad de transporte aéreo de pasajeros en Francia a través de una completa infraestructura comercial, técnica y humana, sin someterse a las normas de orden público francesas. Sobre estas decisiones véase Guichaoua (2014: 385-390); Fotinopoulou Basurko (2015: 139).

$18 \mathrm{Y}$ es aquí donde, en nuestra opinión, radica uno de los mayores logros del legislador europeo, máxime si tenemos en cuenta las dificultades que rodearon la redacción de dicho precepto. De hecho, quién haya seguido con cierto interés el devenir jurisprudencial y normativo de los desplazamientos transnacionales conoce que una de las nociones más compleja es, precisamente, la de «trabajador desplazado temporalmente». Véase la sentencia del Tribunal Superior de Justicia de Oviedo, Sala de lo Social, de 1 de febrero de 2013 anotada por Carballo Piñero (2013-2: 326-330).

19 La información deberá incluir, en particular, la relativa a las diferencias cuantías de salario mínimo y sus conceptos, los métodos para calcular su remuneración y, en su caso, los criterios cualitativos de clasificación en las diferentes categorías salariales (art. 5.4 de la Directiva 2014/67). 
compatibles con el derecho de la UE ex art. 9 de la Directiva 2014/6720 (Llobera Vila, 2017:201-203), proteger de forma efectiva al trabajador (art. 11 de la Directiva 2014/6721), así como facilitar la ejecución de sanciones y multas transfronterizas (art. 13 de la Directiva 2014/67).

\section{LA ADAPTACIÓN AL NUEVO DERECHO UE DE DESPLAZAMIENTO TEMPORAL DE TRABAJADORES EN EL MARCO DE UNA PRESTACIÓN TRANSNACIONAL DE SERVICIOS: ESPECIAL REFERENCIA AL SISTEMA ESPAÑOL}

\section{INTRODUCCIÓN}

Como hemos tenido oportunidad de analizar, son cinco los ejes sobre los que pivotaba la Directiva 2014/67 para mejorar, implementar y garantizar la aplicación de las garantías establecidas en la Directiva 96/71/CE. A tal fin, el nuevo derecho de la UE asigna obligaciones, fundamentalmente, a la Comisión Europea (arts. 8, 9.5, 12.7 y 24), a los Estados miembros, a las autoridades encargadas de aplicar sus disposiciones y a los interlocutores sociales (art. 5). Con todo, la clave del éxito de la mencionada directiva dependía, por una parte, de cómo se implementara en los diferentes Estados (medios humanos y materiales), y, por otra, de cómo se incorporaran sus disposiciones

20 El legislador de la UE europeo limita las exigencias administrativas que el Estado de acogida puede exigir a las empresas que desplacen trabajadores a dicho Estado. Una lista que, a nuestro juicio, en modo alguno constituye una lista cerrada, puesto que el apartado segundo de dicho precepto establece los casos y las condiciones en los que los Estados miembros pueden imponer otras medidas distintas, que no gozan de dicha presunción de legitimidad debiendo acreditar su justificación y proporcionalidad en contra, Martín Hernández (2017: 340)—.

21 Según este precepto, los trabajadores desplazados podrán individual o colectivamente entablar la oportuna acción judicial ante los órganos jurisdiccionales del Estado miembro en cuyo territorio esté o haya estado desplazado el trabajador. Sin perjuicio, en su caso, de la facultad de entablar una acción judicial en otro Estado, de conformidad con lo establecido en los instrumentos de la Unión o los convenios internacionales pertinentes. Dicho precepto no solo aumenta —al menos en teoría, dado que en la práctica puede tener escasa virtualidad-como ya hiciera en su día el art. 6 de la Directiva 96/71, las opciones procesales de las que puede disponer el trabajador a la hora de exigir el cumplimiento de las condiciones de trabajo y empleo establecidas en la ley del Estado de acogida, sino que, además, prevé que lo puede hacer de forma colectiva. 
a los ordenamientos jurídicos internos. En España, esta tuvo lugar a través del Real Decreto Ley 9/201722. Dicha incorporación debe calificarse de tardía e incompleta, puesto que hay preceptos que no han sido incorporados en su totalidad, como sucede con el capítulo VI de la Directiva 2014/67 relativo a la «Ejecución transfronteriza de las sanciones y multas administrativas» ${ }^{23}$. En otros supuestos, la transposición de las directrices contenidas en la directiva ha sido de mínimos, como ocurre con las cuestiones relativas a la cooperación administrativa o a la inspección de trabajo, previstas en el Criterio Técnico núm. 97/2016. No obstante, es de lamentar que el papel asignado a los interlocutores sociales quede muy lejos del rol activo llamado a ser asumido por imperativo de la Directiva 2014/67 (art. 6, apdo. 15). A continuación, procederemos a analizar y a valorar cómo el legislador español ha incorporado las principales obligaciones que dicha directiva establece a nuestro ordenamiento jurídico, para lo cual hemos adoptado un enfoque de derecho comparado.

\section{LAS OBLIGACIONES DIRIGIDAS A LAS AUTORIDADES ENCARGADAS DE APLICAR EL NUEVO DERECHO UE}

Uno de los aspectos problemáticos que planteaba la Directiva 96/71, como hemos apuntado, era la ausencia de conceptos claros y bien definidos, lo que generaba una gran inseguridad jurídica. A tales efectos, la Directiva 2014/67

22 Aunque en nuestro ordenamiento el Criterio Técnico núm. 97/2016 de la Inspección de Trabajo y Seguridad Social sobre el desplazamiento de trabajadores en el marco de una prestación de servicios transnacional anticipaba ya, y en gran medida, el contenido de la misma, así como los mandatos de la jurisprudencia europea (Gómez Abelleria, 2018: 213-232).

23 Así se deduce de lo dispuesto en la disposición adicional séptima de la Ley 45/1999 modificada por el art. 12 del Real Decreto Ley 9/2017. No obstante, tanto el Reino Unido [art. 11 de The Posted Workers (Enforcement of Employment Rights) Regulations, de 2016 —en adelante, Regulations 2016 — disponible en: https://bit.ly/29ohUHt], Irlanda [art. 11 del Statutory Instruments S.I. No. 412 of 2016 in European Union (Posting of Workers) —en adelante, Statutory Instruments_, disponible en: https://bit.ly/2GKleQq], Italia [art. 13 del Decreto Legislativo del 17 luglio 2016 sulla attuazione della Direttiva 2014/67/UE del Parlamento Europeo e del Consiglio, del 15 maggio 2014, concernente l'applicazione della Direttiva 96/71/CE relativa al distacco dei lavoratori nell'ambito di una prestazione di servizi e recante modifica del regolamento (UE) n. 1024/2012 relativo alla cooperazione amministrativa attraverso il sistema di informazione del mercato interno ("Regolamento IMI»), GU n.169 del 21 luglio 2016 —en adelante, Decreto legislativo de 2016-] y Luxemburgo [capítulo IV de la Loi du 14 mars du 2017 —en adelante, Loi du 2017_, disponible en: https://bit.ly/2U9R63J] han procedido a su transposición. 
formuló una lista indicativa, no exhaustiva, de aquellos elementos que pudieran servir a las autoridades competentes para identificar cuándo existe un verdadero desplazamiento temporal de trabajadores en el marco de una prestación transnacional de servicios (art. 4). La práctica existente en los Estados al transponer esta disposición revela que, mientras que hay Estados que no la han incorporado en su ordenamiento (por ejemplo, los derechos inglés e irlandés), otros lo han hecho por referencia (por ejemplo, el derecho luxemburgués ${ }^{24}$ ) o se han limitado a reproducir el texto de la directiva (por ejemplo, los derechos italiano y español ${ }^{25}$ ). Con todo, y como la propia directiva admite, la valoración a realizar por las autoridades nacionales competentes para determinar cuándo existe un verdadero desplazamiento debe ser global, atendiendo a las circunstancias concretas del caso, lo que comporta un amplio y discrecional margen de apreciación por parte de las autoridades nacionales. En dicha evaluación, las autoridades deben tener en cuenta los criterios adoptados por el nuevo derecho de la UE y la doctrina sentada por el TJUE, puesto que a partir de los mismos es, a nuestro juicio, factible diseñar un concepto de "trabajador desplazado». A tenor del cual, trabajador desplazado será todo trabajador, cualquiera que sea su nacionalidad, que preste sus servicios por cuenta ajena y de forma subordinada, con carácter retribuido — con independencia de cómo se caracterice la relación en los acuerdos contractuales o de otro tipo- dentro del ámbito de organización y dirección de un empresario que ejerza actividades sustantivas en el Estado miembro donde está establecido, y que sea desplazado a otro Estado miembro en ejecución de un contrato o a un establecimiento secundario por un periodo limitado de tiempo. Dicho desplazamiento, independientemente de cómo haya sido materializado contractualmente y de si el trabajador ha sido contratado a efectos de ser desplazado o no, debe ser fruto del poder de dirección inherente al empresario o de quién lo ejerza y deberá serlo por un periodo de tiempo determinado o determinable. La duración del mismo constituye un requisito de carácter fáctico, cuya concreción dependerá de las condiciones particulares del mismo, para cuyo cálculo se tendrá en cuenta los periodos previstos en que el puesto haya sido ocupado por el mismo o por el propio trabajador desplazado.

\section{LAS OBLIGACIONES DE INFORMACIÓN, COOPERACIÓN ADMINISTRATIVA, COMPARECENCIA Y PRESENTACIÓN DE DOCUMENTOS}

El texto de la Directiva 2014/67 apostaba decididamente por mejorar el acceso a la información (art. 5) — principio de información gratuita,

24 Art. 2 Loi du 2017.

25 Art. 8 bis de la Ley 45/1999 incluido por el art. 6.5 del Real Decreto Ley 9/2017. 
pública, accesible y comprensible-, fomentar la cooperación y asistencia mutua entre las autoridades nacionales de los Estados miembros (arts. 6-8) y concretar las medidas de vigilancia y seguimiento que los Estados podían establecer para asegurar el efectivo y correcto cumplimiento de la Directiva 96/71 (art. 9).

Un análisis de derecho comparado evidencia que la incorporación de tales obligaciones a los ordenamientos jurídicos de los diferentes Estados ha diferido de un país a otro. En concreto, y a efectos de facilitar la cooperación administrativa, el Real Decreto Ley 9/2017 obliga al empresario que desplace trabajadores a España a comunicar con antelación la fecha en la que su desplazamiento va a producirse, así como, entre otros datos, la identificación de la empresa, la fecha y la duración del desplazamiento ${ }^{26}$. Aunque tales requisitos eran ya contemplados y exigidos en el art. 5 de la Ley 45/1999, el Real Decreto Ley $9 / 2017$ ha añadido a esta disposición dos nuevas previsiones, cumpliendo así con lo estipulado en el art. 9.1 e) y f) de la Directiva 2014/67. Se trata de aspectos que cuentan, sin duda alguna, con una regulación más profusa en la normativa de transposición francesa ${ }^{27}$.

Mención especial merece la regulación que el Real Decreto Ley 9/2017 dispone a cerca de los desplazamientos de trabajadores a España en el marco de un contrato de puesta a disposición. En tales casos, dicha comunicación deberá incluir, además, la acreditación de que el trabajador reúne los requisitos exigidos por la legislación de establecimiento para ponerlo a disposición de una empresa usuaria, así como la precisión de las necesidades temporales de dicha empresa, requerimientos estos que se hallaban ya previstos en el art. 5 de la Ley 45/1999 — modificado por el art. 6 del Real Decreto Ley 9/2017-, aunque no lo están en el texto de la directiva. La cuestión que se plantea, por tanto, es saber si tales exigencias resultarán de aplicación, puesto que, según lo estipulado en el art. 9.2 de la Directiva 2014/67, solo podrán imponerse aquellos otros requisitos distintos a los previstos en el art. 9.1 de la Directiva 2014/67 cuando surjan situaciones o nuevos elementos que evidencien que los requisitos administrativos y las medidas de control existentes resultan insuficientes

26 La comunicación se hará por medios electrónicos en el modo en que se determine reglamentariamente. A tales efectos, el Ministerio de Empleo y Seguridad Social establecerá un registro electrónico central de tales comunicaciones de acuerdo con las comunidades autónomas (art. 5 de la Ley 45/1999 modificado por el art. 6.2 del Real Decreto Ley 9/2017).

27 Arts. R1263-1 a R1263-6 del Décret n. ${ }^{\circ}$ 2015-364 du 30 mars 2015 relatif à la lutte contre les fraudes au détachement de travailleurs et à la lutte contre le travail illégal (en adelante, Décret n. ${ }^{\circ}$ 2015-364), disponible en: https://bit.ly/2Exbdni. 
para garantizar la supervisión efectiva del cumplimiento de las obligaciones establecidas en la Directiva 96/71, y siempre que estos estén justificados y sean proporcionados, es decir, sean compatibles con el derecho de la Unión Europea. Del mismo modo, cabe significar lo establecido en la normativa de transposición italiana, que prescribe obligaciones concretas y precisas para los desplazamientos habidos en el sector del transporte por carretera (art. 1 bis del Decreto legislativo de 2016).

Por su parte, los empresarios que desplacen trabajadores a España deberán, según lo establecido en el art. 6 de la Ley 45/1999, modificado por el Real Decreto Ley 9/2017, comparecer y aportar cierta documentación a la Inspección de Trabajo y Seguridad Social. Se incorpora así al ordenamiento español lo establecido en el art. 9.1 a), b) y c) de la Directiva 2017/67. Dicha documentación deberá presentarse traducida al castellano o a las lenguas cooficiales de los territorios donde se vayan a prestar los servicios [art. 9.1 d) de la Directiva 2014/67]. Este requerimiento de traducción es exigido también en derecho italiano, en el que se estipula, además, que dicha información deberá estar disponible tanto en inglés como en italiano (art. 7.2 del Decreto legislativo de 2016).

Mención especial merece uno de los requisitos enumerados en el art. 6 de la Ley 45/1999, modificado por el Real Decreto Ley 9/2017: la necesidad de acreditar la autorización para trabajar de los nacionales de terceros países de conformidad con la legislación del Estado de establecimiento, exigencia que contempla también la normativa francesa ${ }^{28}$, aunque no se halle expresamente prevista en el art. 9.1 de la Directiva 2014/67. La cuestión radica en determinar si dicha exigencia podría ser exigida. Según lo establecido en el art. $9.2 \mathrm{de}$ la directiva, como hemos visto, solo podría serlo si superara el test de compatibilidad con el derecho de la UE.

Por lo que se refiere a la obligación de información que la directiva incorpora (art. 5), ni en la normativa de transposición inglesa (Regulations 6 ) ni en la irlandesa (Statutory Instruments) se establece nada al respecto. España aprueba en este aspecto, al disponer de una página web en la que se ofrece la información actualizada, tal y como se exige desde las instancias comunitarias. No obstante, consideramos un acierto la creación, como así ha hecho el legislador italiano, de un observatorio destinado a garantizar una mejor difusión entre empresas y trabajadores de las condiciones de trabajo y de empleo (art. 6 del Decreto legislativo de 2016).

28 Art. 1 del Décret no 2015-364. 


\section{HACIA UN MARCO NORMATIVO MÁS SEGURO, JUSTO Y ESPECIALIZADO EN LA UE PARA LOS TRABAJADORES DESPLAZADOS}

\section{INTRODUCCIÓN}

A pesar de las indudables mejoras introducidas en la Directiva 2014/67, estas se revelaron insuficientes. Por lo que la Comisión pronto presentó una propuesta de reforma de la Directiva 96/71, cuya adopción ha tardado más de dos años, dada la división existente dentro de la UE entorno a su adopción y su contenido. La Directiva 2018/957 modifica el texto de la Directiva 96/71, como hemos visto, con un doble objetivo. Por una parte, incrementar la protección laboral del trabajador desplazado. Una cuestión que puede variar, como veremos, en función de que el trabajador desplazado sea calificado o no de larga duración, tal y como lo define la norma. A tales efectos, establece qué derechos laborales deben garantizar las empresas a los trabajadores que son desplazados a otros Estados, cuándo deben ser aplicados estos y en qué instrumentos normativos pueden estar previstos. Y, por otra parte, trata de combatir los abusos detectados en tales desplazamientos, para lo que prevé una serie de medidas.

\section{NUEVA CATEGORÍA JURÍDICA: DEL TRABAJADOR TEMPORALMENTE DESPLAZADO EN EL MARCO DE UNA PRESTACIÓN TRANSNACIONAL DE SERVICIOS AL TRABAJADOR DESPLAZADO DE LARGA DURACIÓN}

En el carácter temporal de la prestación de servicios reside actualmente la justificación del tratamiento diferenciado de los trabajadores desplazados respecto de los trabajadores migrantes. Por ello, es importante saber cuándo un trabajador debe ser considerado como trabajador temporalmente desplazado. $Y$ es que, a pesar de los esfuerzos realizados en la Directiva 2014/67 para concretar dicha noción, no se logró acabar con la «inseguridad jurídica» que rodea a este tipo de desplazamientos. Ante este escenario, la propuesta de reforma de 2016 daba un paso más. Fijaba el límite máximo temporal que un trabajador podía estar desplazado en otro Estado miembro para que el desplazamiento pudiera ser calificado de temporal. De forma que, transcurrido dicho plazo de tiempo, la ley aplicable a dicha relación laboral sería la del Estado de acogida (art. 1 de la propuesta de directiva de 2016) ${ }^{29}$.

29 En concreto, el legislador de la UE establecía el límite de veinticuatro meses, referente a la duración real o prevista del desplazamiento, para determinar la existencia o no de 
La Directiva 2018/957 establece que en caso de que los desplazamientos se prolonguen durante más de doce meses, los Estados miembros de acogida deben velar por que las empresas que desplazan trabajadores a su territorio garanticen a dichos trabajadores un conjunto de condiciones de trabajo adicionales que se aplican obligatoriamente a los trabajadores en el Estado miembro donde se efectúa el trabajo (art. 3.1 bis). Un periodo que el legislador de la Unión estima que puede prorrogarse a dieciocho meses cuando el prestador del servicio así lo notifique (art. 3.1 bis). Se introduce así una nueva categoría jurídica, a saber: la del trabajador desplazado de larga duración. Así, un trabajador temporalmente desplazado podrá pasar a ser desplazado de larga duración una vez que hayan transcurrido doce meses desde que se inició el desplazamiento, con posibilidad de ampliar dicho status seis meses más (hasta dieciocho meses). Después de este periodo, es decir, máximo 18 meses, debe entenderse que el trabajador desplazado estará sujeto en su totalidad a legislación laboral del país de acogida. De esta manera, el legislador de la UE soluciona, de forma definitiva, la cuestión de la temporalidad del desplazamiento y lo hace de forma negativa, es decir, señala el máximo de tiempo que un trabajador puede ser desplazado a otro Estado para ser considerado como trabajador temporal (sea de larga duración o no). En consecuencia, no podrá ser considerado como trabajador desplazado aquel que lo sea por más de dieciocho meses. Sin embargo, esta solución no está, a nuestro juicio, exenta de problemas por dos razones. La primera, porque con el establecimiento de una fecha determinada se corre el riesgo de que dicha solución no se ajuste a determinados tipos de desplazamiento y genere, además, comportamientos fraudulentos por parte de los empresarios. Y, la segunda, por los problemas de coordinación e imbricación que dicha solución puede generar entre el Reglamento Roma I (Mankowski, 2009: 204-207; Henze, 2017; De Götzen, 2014: 540-544) y el texto de la de directiva. De hecho, este ha sido uno de los argumentos esgrimidos por Hungría (asunto C-620/18) en el recurso de anulación que ha presentado contra la mencionada directiva. $Y$ ello porque para la directiva es evidente que, si un trabajador no puede ser calificado de temporal, su régimen laboral estará sometido en su totalidad la ley del Estado de acogida, lo que supondría, por tanto, una modificación del régimen laboral aplicable de dicho trabajador. No obstante, el hecho de que se produzca o no un cambio en la ley aplicable al contrato de trabajo, no puede depender de

un desplazamiento temporal. De modo que, si la duración prevista del desplazamiento fuera superior a dicho plazo, debería aplicarse íntegramente la legislación laboral del Estado de acogida. Un plazo de tiempo que los mismos interlocutores sociales calificaban de excesivo. 
los criterios adoptados en el texto de una directiva, sino de lo que establezca, a tales efectos, el propio reglamento europeo y de cómo en él se interprete el criterio de la "temporalidad». No olvidemos que son dos textos que persiguen objetivos bien distintos. Mientras que el primero cubre las necesidades que se derivan del correcto funcionamiento del mercado interior, el Reglamento Roma I tiene eficacia universal (art. 2) y está destinado a generar mayor seguridad jurídica en las transacciones comerciales transfronterizas y eliminar los problemas de forum shopping. Por lo tanto, los criterios establecidos en la primera no pueden servir a priori para resolver los problemas de aplicación e interpretación de la segunda, salvo que se produzca una modificación del reglamento en tal sentido o que por vía interpretativa el TJUE adopte los criterios establecidos en el texto de la directiva para resolver los problemas interpretativos que dicha noción suscita en el Reglamento Roma I. La cuestión no resulta baladí, pues dicho concepto es más amplio en este texto normativo. Este debe ser interpretado a tenor de lo establecido en su considerando 36. A tenor del cual, la realización del trabajo en otro país se considera temporal cuando se supone que el trabajador va a reanudar su trabajo en el país de origen tras realizar su tarea en el extranjero. Por lo que, podría darse el caso de que el periodo de desplazamiento fuera superior a dieciocho meses, y que el trabajador tuviera ánimo de regresar. Dicho trabajador sería calificado como temporal al amparo de lo establecido en el Reglamento Roma I, pero no así para la directiva. Para sortear dicha contradicción, el legislador de la UE debería haber incluido una cláusula estipulando que el régimen laboral de aquellos trabajadores que no pudieran ser calificados de «desplazados» sería el previsto en dicho reglamento.

\section{LA PROTECCIÓN LABORAL DEL TRABAJADOR DESPLAZADO EN LA DIRECTIVA 2018/957}

\subsection{Las garantías laborales de los trabajadores desplazados}

La Directiva 2018/957 obliga a los empresarios que desplacen trabajadores a otro Estado miembro a asegurarles una serie de garantías laborales establecidas en el Estado de acogida, salvo que existan otras más favorables. Unas garantías que, como veremos, pueden variar dependiendo del tiempo que los trabajadores sean o vayan a ser desplazados a otro Estado miembro, es decir, de si tales trabajadores son considerados como trabajadores desplazados temporalmente (hasta doce meses) o como trabajadores desplazados de larga duración (de doce a dieciocho meses). En particular, los trabajadores temporalmente desplazados en el marco de una prestación transnacional de servicios gozarán de las garantías laborales establecidas en la legislación del Estado de 
acogida previstas en el art. 3.1 de la Directiva 96/71 —modificado por la Directiva 2018/957 - . A tenor de dicho precepto, han aumentado las garantías de las que pueden gozar los trabajadores desplazados temporalmente, es decir, aquellos que lo son por menos de doce meses. Además de las previstas en el art. 3 de la Directiva 96/71, los trabajadores desplazados deberán gozar de las condiciones de alojamiento establecidas en la legislación del Estado de acogida [art. $3.1 \mathrm{~h}$ )] y deberán recibir al menos los mismos complementos o los mismos reembolsos en conceptos de viaje, alojamiento y manutención por estancia que un trabajador fuera de su domicilio por motivos profesiones ${ }^{30}$.

En principio, tales garantías son las únicas que se podrán exigir al prestador de servicios que desplace trabajadores de forma temporal a otro Estado miembro y, por tanto, las que deberán compararse con las disposiciones nacionales de la ley que rija el contrato, para acabar aplicando las más favorables (art 3.5). A este tipo de trabajadores la Directiva 2018/957 les reconoce, pues, una protección materialmente limitada, aunque los Estados podrán ampliarla, dada la posibilidad que tienen de disponer que a este tipo de trabajadores se les apliquen otras exigencias distintas a las previstas en el art. 3 de la Directiva 96/71, siempre que se traten de disposiciones de orden público. No obstante, aunque las normas reguladas en la incorporación de la directiva tengan carácter de normas de orden público, no hay que olvidar que la posibilidad de aplicar tales normas estaría amparada por el art. 9 del Reglamento Roma I (art. 7 del Convenio de Roma sobre ley aplicable a las obligaciones contractuales de $\left.1980^{31}\right)$, pero sin contar con el respaldo del derecho de la $\mathrm{UE}^{32}$, lo que implica que para su aplicación debe verificarse su compatibilidad con aqueli3.

Mención especial merece la protección que la Directiva 2018/957 reconoce a los trabajadores desplazados por una empresa de trabajo temporal o agencia de colocación. A fin de evitar la discriminación existente entre los

30 Ello será así siempre que los trabajadores desplazados deban viajar a y desde su lugar habitual de trabajo situado en el Estado miembro en cuyo territorio estén desplazados, o cuando su empleador los envíe temporalmente desde dicho lugar habitual de trabajo a otro lugar [art. 3.1 i) de la Directiva 2018/957].

31 DO 266, de 9 de octubre de 1980, p. 1.

32 De hecho, el TJUE ha declarado que el art. 9 del Reglamento Roma I es de interpretación restrictiva, de manera que solamente pueden aplicarse como normas jurídicas las normas de policía del Estado del foro o las del Estado en el que las obligaciones derivadas del contrato de trabajo tienen que ejecutarse o han sido ejecutadas. Por tanto, las normas de policía de ordenamientos distintos a los mencionados pueden ser tomadas en consideración como circunstancias de hecho (Sentencia de 18 de octubre de 2016, Nikiforidis, 135/15, EU:C:2016:774).

33 Sentencia de 23 de noviembre de 1999, Arblade, 369/96 y 376/96. 
trabajadores locales y los desplazados, la Directiva 2018/957 añade un nuevo apartado al art. 3 de la Directiva 96/71 (1 ter), en el que se obliga a los Estados miembros a asegurar que las empresas de suministro de mano de obra que desplacen trabajadores a otro país les garanticen los mismos derechos que las empresas establecidas en el Estado de acogida dan a sus trabajadores (ex art. 5 de la Directiva 2008/104/CE del Parlamento y del Consejo de 19 de noviembre de 2008, relativa al trabajo a través de empresas de trabajo tempo$\left.\mathrm{ral}^{34}\right)$. De esta manera, lo que conforme a esta directiva era una opción para los Estados, la Directiva 2018/957 lo convierte en un mandato legal que se impone a todos los Estados miembros, evitando así los problemas de interrelación existentes entre las directivas 96/71 y 2008/104 (Van Hoek y Houwerijl, 2011: 185-186; Cairós Barreto, 2017: 147-148). No obstante, estas no son las únicas garantías de las que pueden gozar este tipo de trabajadores. La Directiva 2018/957 reserva cierto margen de actuación a los Estados miembros. Estos podrán exigir que a los trabajadores desplazados por empresas de suministro de mano de obra les sean de aplicación otras condiciones de trabajo, distintas a las contempladas en el al art. 5 de la Directiva 2008/104, previstas para los trabajadores temporales en el Estado miembro en cuyo territorio se ejecute el trabajo. Dicha posibilidad será, a nuestro juicio, factible siempre estas no resulten incompatibles con la libertad de prestación de servicios. Una restricción que, aunque no está expresamente prevista, resulta obvia si tenemos en cuenta la base jurídica y lo expresado por el legislador de la UE en los distintos considerandos.

Con todo, la novedad más destacable de la Directiva 2018/957 respecto de los trabajadores desplazados temporalmente - y desde nuestra perspectiva, lo que constituye un paso decisivo en su efectiva protección- es la supresión de la restricción existente en la Directiva 96/71 sobre qué instrumentos jurídicos - de los previstos en el Estado de acogida que regulan tales garantíasresultan aplicables. La Directiva 96/71 delimitaba las normas del Estado de acogida aplicables no solo en función de la materia, sino también de la naturaleza del instrumento jurídico en el que se encontraban reguladas. Esta exigía la aplicación solo de los convenios colectivos o laudos arbitrales declarados de aplicación general en el sector de la construcción (art. 3.1 y anexo de la Directiva 96/71). Con dicha supresión, un trabajador desplazado temporalmente a otro Estado podrá gozar de las garantías establecidas y previstas en cualquier convenio colectivo con independencia de la actividad que desempeñe aquel — sea en el sector de la construcción o no-. Esta modificación, aparentemente formal, vislumbra una modificación sustancial y loable, pues implica

34 DO L 327/9, de 11 de abril de 2006, p. 1. 
que los convenios colectivos de aplicación general a tenor del art. 3.8 de la Directiva 96/71 deberán ser aplicados a los trabajadores desplazados en todos los sectores de la economía con independencia de que las actividades que desempeñen en el Estado de acogida estén o no contempladas en el anexo de la Directiva, sobre todo, y, en particular, para aquellos Estados que, a diferencia de lo que sucede en derecho español (art. 3 de la Ley 45/1999), limitaron su aplicación a los supuestos previstos en el anexo ${ }^{35}$.

No obstante, la mayor gesta de la directiva europea afecta a aquellos trabajadores a los que califica como «trabajadores desplazados de larga duración», es decir, aquellos que son desplazados más de doce meses hasta un máximo de dieciocho, puesto que estos gozarán de todas las garantías previstas en la normativa del Estado de acogida, a excepción de ciertas prerrogativas establecidas en la directiva (art. 3 bis de la Directiva 96/71 modificado por la Directiva $2018 / 957)^{36}$.

La solución adoptada constituye, sin duda alguna, la mayor aportación y el mayor paso dado por el legislador de la UE para lograr la efectiva protección de los derechos de los trabajadores desplazados, pues proclama el "principio igualdad de trato» entre estos y los trabajadores locales, lo que supone un viraje significativo en este ámbito, donde los derechos de los trabajadores han sido tradicionalmente sacrificados por mor de la libre prestación de servicios. De hecho, la proclamación de este principio ha sido uno de los argumentos esgrimidos por Polonia en el recurso de anulación que ha presentado contra la presente directiva, y cuya solución requerirá de un análisis exhaustivo de la jurisprudencia consolidada por el TJUE en este ámbito, puesto que las restricciones a la libre prestación de servicios solo son admisibles si están justificadas por razones imperiosas de interés general y si son proporcionadas y necesarias. A nuestro juicio, y a tenor de lo expuesto en la jurisprudencia de dicho tribunal, existe un evidente interés general (la protección del trabajador) que justificaría dicha restricción (Arblade y Portugaia) ${ }^{37}$. La clave para resolver si la disposición impugnada es compatible o no con el derecho de la UE estará, a nuestro juicio, en concretar si dicha restricción es proporcional y necesaria.

35 En efecto, según el art. 3 de la Ley 45/1999, se obliga al empresario que desplace trabajadores a nuestro país a garantizar las condiciones legales recogidas en el art. 3.1 de la Ley 45/1999 con independencia del tipo de desplazamiento que se efectúe, de la actividad a desarrollar y la duración del mismo.

36 En concreto, no les serán de aplicación los procedimientos, formalidades y condiciones de celebración y de resolución del contrato de trabajo con inclusión de las cláusulas de no competencia y los regímenes de jubilación.

37 Sentencia de 23 de noviembre de 1999, Arblade, 369/96 y 376/96, EU:C:1999:575; Sentencia de 24 enero de 2002, Portugaia, 164/99, EU:C:2002:40. 
Se modifican, pues, la filosofía y la forma de proteger a este tipo de trabajadores en el ámbito europeo y, en concreto, a los trabajadores desplazados de larga duración. Para estos, la nueva regulación europea cambia de modelo de protección. Si la Directiva 96/71 se limitaba a establecer el «mínimo común denominador» de protección que se garantizaba al trabajador desplazado, el nuevo derecho de Europa adopta un nuevo enfoque basado en el «máximo común denominador».

En conclusión, para la Directiva 2018/957, la protección de los trabajadores desplazados en el marco de una prestación transnacional de servicios estará limitada a ciertas materias, es decir, será de mínimos (art. 3 de la Directiva 96/71), o podrá ser de máximos (principio de igualdad de trato), según sea la duración del desplazamiento del trabajador (si este es de larga duración o no), el tipo de desplazamiento que tenga lugar (si se enmarca o no dentro de un contrato de puesta a disposición o no) y de cómo los Estados incorporen las disposiciones de la Directiva 2018/957 a sus respectivos ordenamientos.

En cualquier caso, y a pesar de las novedades incorporadas en el texto de la directiva, es de lamentar que la Directiva 2018/957 no recoja una previsión expresa — cosa que sí estaba presente en la propuesta de directiva de 2016otorgando a los Estados la facultad de obligar a las empresas a subcontratar solo con empresas que concedan a los trabajadores determinadas condiciones de remuneración aplicables al contratista, lo que hubiera permitido imponer cláusulas sociales a empresas que desplazan sus servicios a otros Estados (Guamán Hernández, 2016: 126). En su lugar, la Directiva 2018/957 insta a los Estados miembros a adoptar las medidas adecuadas, de conformidad con el art. 12 de la Directiva 2014/67, para garantizar la responsabilidad en materia de subcontratación (considerando 25).

\subsection{Del salario mínimo al principio de «igualdad salarial»}

La Directiva 96/71 garantizaba a los trabajadores temporalmente desplazados la aplicación solo de un «núcleo duro» de disposiciones laborales reconocidas en el Estado de acogida (art. 3). Establecía, pues, el «mínimo común denominador» que debía ser aplicado y respetado en todos los Estados miembros, siempre que ello fuera más favorable al trabajador (principio pro operario $)^{38}$. Por lo que a la cuestión salarial se refiere, obligaba a que se

38 De hecho, dicho principio puede modular la aplicación de las normas imperativas del Estado de acogida, puesto que, si la protección que otorgan las disposiciones imperativas del Estado miembro de acogida es menos favorable que la del Estado de origen, estas no deberían ser aplicadas. 
garantizase al trabajador el «salario mínimo» estipulado en el Estado de acogida en los términos en los que su normativa establecía. En concreto, solo garantizaba el salario reconocido en determinados instrumentos normativos (arts. 3.1 y 3.8 de la Directiva 96/71) en aquellos casos en los que el trabajador realizase ciertas actividades (las enumeradas en el anexo), y siempre y cuando dicha obligación no fuera susceptible de ser exceptuada (art. 3.2, 3, 4 y 5 de la Directiva 96/71) ${ }^{39}$.

Precisamente, si tenemos en cuenta que la cuestión salarial constituye uno de los elementos centrales causantes de las desigualdades entre las empresas que trasladan trabajadores y las locales ${ }^{40}$, resultaba lógico pensar que su concreción sería una cuestión a regular por la Directiva 2014/67. No obstante, esta se limitó solo a establecer que: para garantizar la correcta remuneración del trabajador desplazado, los complementos específicos por desplazamiento, siempre que puedan considerarse salario mínimo, deben descontarse de la remuneración solo si la normativa, los convenios colectivos y las prácticas nacionales del Estado miembro de acogida así lo establecen (considerando 35).

En conclusión, el "principio de igualdad de trato» en materia salarial no estaba garantizado ni en la Directiva 96/71 ni en la Directiva 2014/67 (Fotinopouloy y Larrazabal, 2015: 252-271). De ahí que el aspecto más destacado y novedoso de la propuesta de directiva de 2016 fuera, precisamente, la proclamación de dicho principio en materia salarial. Esta novedad suponía un cambio decisivo en relación con en el modelo que seguía la Directiva 96/71, puesto que del «mínimo común denominador» de protección para el trabajador desplazado se pasaba a un nuevo enfoque basado en el «máximo común denominador» en materia salarial (Molina Navarrete, 2016: 12).

El nuevo derecho de la UE adopta este último modelo. Reconoce el «principio de igual de trato» en materia salarial. Contempla, por tanto, una protección de máximos en materia salarial. Una decisión de política legislativa

39 El art. 3.2 contiene una excepción de carácter obligatorio en aquellos casos en los que la duración del desplazamiento para determinadas actividades - trabajos de montaje inicial o de primera instalación de un bien- no exceda los ocho días, excepción que no se aplica a los trabajadores del sector de la construcción. De la misma manera, los apdos. 3, 4 y 5 del art. 3 contemplan que los Estados miembros podrán excluir la aplicación de las cuantías del salario mínimo cuando la duración del desplazamiento no sea superior a un mes y los desplazamientos sean realizados en el marco de una contrata o en un grupo de empresas (3 y 4) o cuando los trabajos a desarrollar sean de escasa importancia (5).

40 Así como las dificultades existentes para su determinación, como así lo atestigua la Sentencia de la Cour de Cassation (Soc.) francesa de 13 de noviembre de 2014 anotada por Jault Seseke (2015: 360). 
que merece ser saludada, puesto que abraza tanto a los trabajadores desplazados temporalmente como a los trabajadores desplazados de larga duración. En concreto, y en relación con los primeros, la directiva obliga a los Estados miembros a que el régimen de remuneración aplicable a los trabajadores locales establecidos en disposiciones legales, reglamentarias o administrativas, en laudos arbitrales o convenios colectivos - tal y como se definen en el art. 3.8 de la Directiva 96/71 modificado por la Directiva 2018/957- sea, igualmente, aplicable a los trabajadores desplazados. La solución acuñada cabe calificarse de histórica, ya que obliga a que le sea garantizado no solo el salario mínimo establecido en la normativa del Estado de acogida, como ocurría anteriormente, sino todos los elementos que sean de obligado pago a los trabajadores locales.

En particular, la Directiva 2018/957 establece que el concepto de remuneración vendrá determinado por la legislación o las prácticas nacionales del Estado miembro en cuyo territorio está desplazado el trabajador, y comprenderá todos los elementos constitutivos de la remuneración obligatorios en virtud de las disposiciones legales, reglamentarias o administrativas nacionales o de los convenios colectivos o laudos arbitrales (art. 3.8).

Establece también, como así hiciera la Directiva 96/71, que los complementos específicos por desplazamiento serán considerados parte de la remuneración, en la medida en que no se abonen como reembolso de los gastos efectivamente realizados a causa del desplazamiento (gastos de viaje, alojamiento, etc.). La novedad que incorpora el nuevo derecho de la Unión Europea en este ámbito radica en que dispone que el empresario reembolsará a los trabajadores desplazados estos gastos de conformidad con la legislación o las prácticas nacionales aplicables a la relación laboral. De forma que, si no se indica si los elementos del complemento específico por desplazamiento se abonan en concepto de reembolso de gastos efectivamente realizados y, en su caso, cuáles son esos elementos, se considerará que la totalidad del complemento se abona en concepto de reembolso de gastos (art. 1 de la Directiva 2018/957).

A nuestro juicio, la fórmula empleada por la Directiva 2018/957 para regular la cuestión salarial se compadece bien con las tradiciones existentes en los Estados miembros de la Unión, en la medida en que no interfiere ni en las competencias de los Estados ni en los mecanismos de fijación de los salarios existentes en los diferentes Estados miembros, aunque, desde nuestro punto de vista, el legislador de la UE podía haber hecho acopio de la doctrina pronunciada en diferentes sentencias, en concreto, en las dictadas el 14 de abril de 2005, el 7 de noviembre de 2013 y, en particular, en la dictada 12 de febrero de 2015 (Corneloup, 2015: 650), en las que el TJUE perfiló una serie de parámetros a partir de los cuales se podía construir un concepto europeo de retribución/«salario mínimo» a garantizar a los trabajadores desplazados en 
el marco de una prestación de servicios. A tenor de los cuales, dicho concepto depende del:

Derecho del Estado miembro de acogida, siempre que la definición que resulte de la legislación o de los convenios colectivos aplicables no tenga el efecto de obstaculizar la libre prestación de servicios entre los Estados miembros (Isbir). Puede ser el salario fijado por horas y/o a destajo, basado en la clasificación de los trabajadores en grupos salariales, si así está previsto en los convenios del Estado de acogida, siempre que dichas reglas sean vinculantes y transparentes (Sähköalojen ammattiliiito ry). Se considerará que forman parte de dicho salario tanto la indemnización prevista en convenio en forma de pago diario de cantidad fija que compensa los inconvenientes del desplazamiento como el complemento de trayecto diario (complemento que compensa el tiempo de trayecto diario entre el centro de trabajo y el alojamiento) o la paga de vacaciones forman parte del salario mínimo (Sähköalojen ammattiliiito ry). Y, en definitiva, cualquier concepto de remuneración que no modifique la relación entre la prestación del trabajador, por una parte, y la contraprestación que este percibe como remuneración de aquella prestación, por otra (Isbir). Por el contrario, no se considerará como tal ni el pago realizado a los trabajadores por alojamiento ni los denominados cheques-restaurante (Sähköalojen ammattiliiito ry). Tampoco podrán tener dicha consideración los incrementos ni los complementos que no formen parte del salario mínimo ni por la legislación ni por las prácticas nacionales existentes en cuyo territorio haya sido desplazado el trabajador y que modifican la relación entre la prestación del trabajo, por un lado, y la contraprestación que percibe, por otro (Comisión/República Federal de Alemania) ${ }^{41}$.

A pesar de esto, la Directiva 2018/957 marca una tendencia clara en la regulación de esta materia en una opción que pretende guardar un efectivo equilibrio entre la protección efectiva del trabajador y la libre prestación de servicios de las empresas europeas, aunque para Polonia, precisamente, las disposiciones de la directiva relativas a la remuneración de los trabajadores desplazados supongan una restricción a la libre prestación de servicios.

En suma, y sin lugar a dudas, el derecho de la Unión Europea parece haber cambiado de rumbo en la protección del trabajador desplazado. Observada la iniciativa europea bajo esta perspectiva, creemos que la regulación adoptada cumple en un grado alto con las exceptivas que se habían generado.

41 Sentencia de 14 de abril de 2005, Comisión/República Federal de Alemania, 341/02, EU:C:2005:220; Sentencia de 7 noviembre de 2013, Tevfik Isbir, 522/12, EU:C:2013:711; Sentencia de 12 de febrero de 2015, Sähköalojen Ammattiliitto ry, 396/13, EU:C:2015:86. 
Ahora queda el reto de su puesta en funcionamiento por parte de los Estados miembros — si la directiva no se anula—, lo cual, consideramos, puede ser una buena oportunidad para revisar y mejorar los sistemas estatales.

\section{COORDINACIÓN, COOPERACIÓN, TRANSPARENCIA, CORRESPONSABILIDAD Y SEGURIDAD JURÍDICA CONTRA EL ABUSO Y FRAUDE EMPRESARIAL}

Para proteger de forma efectiva al trabajador desplazado, la Directiva 2018/957 adopta también una serie de medidas para acabar con el fraude y el abuso tan frecuentes en este ámbito. A tales efectos, reitera la necesidad de reforzar la coordinación y la cooperación entre las autoridades y organismos competentes de los Estados miembros (art. 4.2 de la Directiva 96/71 modificado por la Directiva 2018/957) y reconoce la corresponsabilidad del Estado de origen y del de acogida en las labores de vigilancia, control y ejecución de las obligaciones contempladas en la directiva (art. 5 de la Directiva 96/71 modificado por la Directiva 2018/957). Y es que del cumplimiento y la ejecución efectiva y eficiente de las disposiciones de la directiva dependerá su éxito. Por ello, consideramos un acierto el esfuerzo realizado por el legislador de la UE en la Propuesta de Reglamento del Parlamento Europeo y del Consejo por el que se crea la Autoridad Laboral Europea ${ }^{42}$, en la que se pretende crear un organismo europeo que vele por el cumplimiento de los textos jurídicos que afecten al contenido y ámbito laboral y que refuerce los controles y la coordinación entre los Estados miembros (Monereo y Ortega, 2018: 1-14).

De la misma manera, el legislador de la UE, conocedor de la importancia que tiene que los trabajadores conozcan cuáles son las garantías sociales de las que pueden disfrutar de forma accesible y trasparente, impone en la directiva a los Estados miembros la obligación de publicar la información sobre las condiciones de trabajo en el sitio web nacional oficial único, los elementos constitutivos de la remuneración que sean obligatorios, así como el conjunto adicional de condiciones de trabajo aplicables a los trabajadores desplazados de larga duración (de doce a dieciocho meses) ${ }^{43}$.

42 COM (2018) 0064 final, 13-3-2018.

43 Cada Estado miembro deberá, por tanto, garantizar que la información contenida en el sitio web nacional oficial único sea exacta y que sea actualizada periódicamente. De hecho, cualquier sanción que se imponga a una empresa por incumplimiento de las condiciones de trabajo que han de garantizar a los trabajadores desplazados debe ser proporcionada, y la fijación de la sanción debe tener en cuenta, en particular, si la información ofrecida en el sitio web nacional oficial único acerca de las condiciones de trabajo cumple con lo dispuesto en el art. 5 de la directiva. 
Por su parte, las situaciones de fraude o abusos detectados en este tipo de desplazamientos justifican la adopción de medidas concretas tendentes a reforzar la dimensión transnacional de las inspecciones, investigaciones e intercambios de información entre las autoridades u organismos competentes de los Estados miembros afectados. A tal fin, en el marco de la cooperación administrativa prevista en las directivas 96/71 y 2014/67 (art.7.4), las autoridades $\mathrm{u}$ organismos competentes deben disponer de los medios necesarios para alertar de la existencia de las mencionadas situaciones. De forma que, cuando tras una evaluación global realizada por un Estado miembro, de conformidad con el art. 4 de la Directiva 2014/67, se compruebe que una empresa está creando, de manera indebida o fraudulenta, la impresión de que la situación de un trabajador entra en el ámbito de aplicación de la presente directiva, dicho Estado miembro velará por que el trabajador se beneficie de la legislación y las prácticas aplicables (Directiva 2018/957).

Mención especial merecen las medidas adoptadas en la Directiva 2018/957 para evitar los llamados desplazamientos sucesivos, que conforman realmente supuestos de desplazamientos permanentes, aunque encubiertos de forma fraudulenta como desplazamientos temporales repetidos. Sin duda, una práctica que produce efectos negativos en el funcionamiento del mercado interior y perjudica, considerablemente, a los derechos que los trabajadores desplazados pueden gozar. Para evitar tales prácticas, la Directiva 2018/957 estipula que cuando una empresa sustituya a un trabajador desplazado por otro trabajador que realice el mismo trabajo en el mismo lugar, la duración del desplazamiento será la duración acumulada de los periodos de desplazamiento de cada uno de los trabajadores desplazados de que se trate. Añade, además, que el concepto de "mismo trabajo en el mismo lugar» se determinará teniendo en cuenta, entre otros elementos, la naturaleza del servicio que se preste, el trabajo que se realice y la dirección o direcciones del lugar de trabajo (art. 1). A pesar de la bondad de esta disposición, es evidente que, para acabar con estos comportamientos fraudulentos, es preciso, a nuestro juicio, contar con mecanismos de vigilancia adecuados, con una cooperación administrativa adecuada y coordinada que permitan controlar y acabar con estas situaciones de abuso. Este es el principal reto que tendrán que cumplir los diferentes Estados miembros.

\section{LA PIEDRA DE TOQUE DEL NUEVO DERECHO DE EUROPA: EL DESPLAZAMIENTO DE LOS TRABAJADORES DEL SECTOR DE TRANSPORTE POR CARRETERA}

El transporte en la Europa en la que vivimos es inseparable del mercado interior, ya que constituye una actividad fundamental para la libre circulación 
de las personas, los bienes y los servicios. Pero dicho componente económico requiere un reverso social, que asegure unas condiciones laborales dignas y adecuadas en un sector en el que la competencia desleal, el dumping social y las prácticas empresariales abusivas (registros de flotas de vehículos en Estados miembros con costes más bajos, creación de empresas buzón, falsos autónomos, etc.) están muy presentes. A ello coadyuva, sin duda alguna, el hecho de que los derechos laborales de estos trabajadores no cuenten con una regulación propia y específica. De hecho, una de las polémicas más enconadas que existen en este ámbito es determinar si a este tipo de trabajadores les resulta de aplicación o no la Directiva 96/71. Para la Comisión, tales trabajadores están comprendidos dentro del ámbito de aplicación de la Directiva 96/71, siempre que la prestación de servicios sea realizada por cuenta y dirección de una empresa que presta servicios a un cliente y que el desplazamiento de tales trabajadores sea parte de dicha prestación ${ }^{44}$. De forma que en aquellos casos en los que tales condiciones no sean observadas, la Directiva 96/71 no resulta de aplicación. Sí lo serían, empero, al transporte de cabotaje, es decir, a las prestaciones realizadas por transportistas no residentes que, con motivo de un desplazamiento internacional, se encuentran en un país de acogida y que, en lugar de volver con el vehículo vacío, efectúan un transporte ulterior dentro de dicho país antes de alcanzar la frontera [art. 8.2 del Reglamento (CE) núm. 1072/2009, del Parlamento Europeo y del Consejo, de 21 de octubre de 2009 por el que se establecen normas comunes de acceso al mercado del transporte internacional de mercancías por carretera ${ }^{45}$.

A tenor de lo expuesto, y con la excepción apuntada, no cabe duda de que los trabajadores transnacionales en el sector del transporte y, en concreto, en el de transporte por carretera, quedan actualmente sometidos a las disposiciones de la Directiva 96/71 [considerando 17 del Reglamento (CE) núm. 1072/2009 y art. 3 de la Directiva 2018/957]. Una decisión que ha provocado las críticas de los sindicatos europeos porque, para estos, la Directiva 96/71 constituye, precisamente, el origen del dumping social que sufre el sector.

Con todo, constituye una movilidad no exenta de problemas (Mankowski, 2017, 1-42). Y es que el legislador de la UE no ha dispuesto cómo debe ser aplicada la Directiva 96/71 a este sector; siendo múltiples los problemas a los que se enfrentan los Gobiernos, las empresas y los sindicatos a la hora de exigir el cumplimiento y control de esta normativa (Llobera, 2018: 517). De hecho,

44 Documento SEC (2006) 439, Commission's Services Report on the Implementation of Directive 96/71/EC Concerning the Posting of Worker in the Framework of the Provisions of Services, [COM (2006) 159 final, 24-1-2015].

45

DO L 72, de 14 de noviembre de 2009, p. 72. 
en la propuesta de directiva de reforma de la Directiva 96/71 de 2016 se hacía eco de las dificultades de aplicación que planteaban la Directiva 96/71 en el sector del transporte internacional por carretera (considerando 10).

A la luz de lo anterior, resulta evidente que urge mejorar las condiciones laborales y sociales de los trabajadores en este sector, propugnando una mayor claridad y respeto de las normas aplicables. La cuestión que se encuentra en el centro del debate político es saber si para ello es preciso formular una norma que regule de forma expresa y concreta el régimen laboral de estos trabajadores o si, por el contrario, es factible adaptando el texto de la Directiva 96/71 a tales supuestos. La Comisión es partidaria de esta última opción. Así, en 2017, presentó una propuesta de directiva para facilitar la aplicación de lo dispuesto en la Directiva 96/71 y en la Directiva 2014/67 a los supuestos de desplazamiento de trabajadores en el sector del transporte por carretera. El objetivo de la misma era garantizar el equilibrio entre unas condiciones de trabajo adecuadas para los conductores y la libertad de los operadores para prestar servicios transfronterizos. Cuestión que, para la Comisión, pasa por saber cuándo existe vínculo suficiente con el Estado miembro de acogida, a efectos de aplicar la normativa europea de desplazamiento. Y, por otra, adecuar las disposiciones sobre el desplazamiento de trabajadores y los requisitos administrativos que son exigidos en estos casos a los supuestos de movilidad de los trabajadores en el sector del transporte internacional por carretera, en la medida en que estas generan cargas reglamentarias excesivas y crea obstáculos injustificados a la prestación de servicios transfronterizos.

En concreto, la propuesta de directiva de 2017 en el sector del transporte establece que la normativa europea de desplazamiento establecida en el Estado miembro de acogida, y en particular lo dispuesto en materia de salario y las vacaciones anuales mínimas, deberá ser aplicada a los trabajadores en el sector del transporte por carretera que realicen transportes internacionales, según se definen en los reglamentos (CE) núm. 1072/2009 y (CE) núm. 1073/200946, a los tres días de su llegada al país de destino (art. 2). Para calcular dicho plazo de tiempo, la Comisión sugiere que menos de seis horas en un Estado cuenten por medio día, frente a un día cuando sean más de seis horas. Este umbral temporal, según establece la propia propuesta, no debe aplicarse a los transportes de cabotaje tal como se definen en los reglamentos (CE) núm. 1072/2009 y (CE) núm. 1073/2009, ya que todo el transporte se realiza en el Estado

46 Reglamento (CE) núm. 1073/2009 del Parlamento Europeo y del Consejo de 21 de octubre de 2009 por el que se establecen normas comunes de acceso al mercado internacional de los servicios de autocares y autobuses y por el que se modifica el Reglamento (CE) núm. 561/2006 (DO L 300, de 14 de noviembre, p. 88). 
miembro de acogida. Además, con objeto de garantizar un control eficaz y eficiente del cumplimiento de dicha normativa y evitar también unas cargas administrativas desproporcionadas en este sector, la propuesta de directiva de 2017 enumera de forma taxativa los requisitos administrativos y de control específicos que se podrán exigir en el sector del transporte por carretera (art. 4).

Sin embargo, algunos Estados miembros, por ejemplo España y Dinamarca, así como distintas asociaciones europeas (por ejemplo ASTIC ${ }^{47}$ y $\mathrm{ITD}^{48}$ ), se han mostrado reacios a que estos trabajadores sean considerados como trabajadores desplazados en el marco de una prestación internacional de servicios y, por tanto, estén incluidos en el ámbito de aplicación de la Directiva 96/71. A su juicio, esta normativa está pensada para un tipo de trabajador que no tiene la alta movilidad que caracteriza a los trabajadores en el ámbito del transporte internacional. No hay que olvidar que los transportistas europeos pueden llegar a atravesar en una sola jornada tres y hasta cuatro fronteras de diferentes Estados miembros de la UE, por lo que para aquellos carece de lógica aplicar una normativa diseñada para trabajadores que realizan actividades laborales durante periodos de tiempo más dilatados (meses o años) en un Estado distinto al de origen del trabajador. Por el contrario, son partidarios de que el estatus laboral de estos trabajadores sea regulado en una norma específica acabando así no solo con los abusos de las empresas transportistas, sino con las soluciones unilaterales desarrolladas hasta la fecha por los Estados miembros (por ejemplo, Francia y Alemania). En concreto, contemplan la elaboración de un reglamento en el que se estipule que las condiciones laborales aplicables a estos trabajadores fueran las del Estado en el que el transportista hubiera contratado el mayor porcentaje de cargas. De esta manera, el control sería más sencillo y efectivo y, por tanto, el trabajador como la empresa tendrían una norma clara a la que adherirse para determinar el coste laboral ${ }^{49}$.

A nuestro juicio, la regulación de las condiciones laborales de los trabajadores en el sector del transporte por carretera, a través de un reglamento europeo, quizás, no sea la opción más aconsejable. Con todo, somos conscientes de la necesidad de formular y consensuar una regulación propia y específica que contemple las condiciones aplicables a los mismos, teniendo presente la alta movilidad que caracteriza a este tipo de trabajadores, lo que requiere de un análisis más exhaustivo de los intereses y las circunstancias que caracterizan a este tipo de trabajadores.

47 Asociación de transporte internacional por carretera

48 Association for de Danish Road Transport of Goods.

49 Disponible en: https://bit.ly/2VkSW27 


\section{CONCLUSIONES}

La Directiva 96/71 ha demostrado ser una norma insuficiente para responder a las necesidades y a las exigencias que existen actualmente en los supuestos de desplazamiento temporal de trabajadores en el marco de una prestación transnacional de servicios. Ello ha obligado al legislador de la UE a su revisión y modificación a través de distintos instrumentos normativos formulados en distintas etapas.

La Directiva 2014/67, aunque debería de haber sido más decidida en materia salarial, supuso la creación de un marco jurídico más previsible y seguro, no solo al establecer una serie de obligaciones y principios dirigidos a los Estados miembros (de información, de cooperación y reconocimiento mutuo), sino también al incorporar una serie de criterios interpretativos a aplicar por las autoridades nacionales competentes para identificar cuándo y a qué tipo de trabajadores debe resultar de aplicación la protección que la Directiva 96/71 establece. Con todo, la clave del éxito de la misma dependía de su efectiva implementación (medios humanos y materiales) e incorporación en los diferentes Estados miembros. El presente estudio ha revelado que la práctica existente en derecho comparado para incorporar sus disposiciones ha sido muy diversa. En España, esta se llevó a cabo a través del Real Decreto Ley $9 / 2017$, una incorporación que, como hemos evidenciado, debe ser objeto de crítica, como así sucede en otros sistemas jurídicos de nuestro entorno, no solo porque la técnica normativa utilizada no ha sido muy depurada, sino porque ha resultado ser tardía, parcial, fragmentada, con ciertas carencias y con disposiciones que pueden llegar a ser, incluso, contrarias al derecho de la Unión Europea. Con todo, se trata de una norma que permite identificar cuándo existe un auténtico desplazamiento trasnacional de trabajadores y evitar los supuestos de fraude tan frecuentes en este ámbito, además de concretar las obligaciones y las formalidades que resultan exigibles cuando los trabajadores son desplazados a territorio español.

Es la reciente Directiva 2018/957 la que tiene el propósito de alinearse en aras de una más efectiva protección del trabajador, lo que supone un viraje significativo en este ámbito, donde los derechos de los trabajadores han sido sacrificados en aras de la libre prestación de servicios. Se trata de una norma que resulta loable, pues incrementa de forma considerable la protección del trabajador desplazado, sobre todo, del que es calificado de "larga duración», confiriéndole una protección de máximos al consagrar el «principio de igualdad de trato", incluso en materia salarial. A su vez, resuelve uno de los principales problemas de interpretación que existe en este ámbito, pues precisa cuándo un desplazamiento debe ser calificado de temporal, aunque, como hemos evidenciado, su concreción no está exento de inconvenientes, puesto 
que acarrea problemas de imbricación entre el texto de la directiva y el Reglamento Roma I. Por otro lado, y para asegurar la aplicación del derecho de protección del trabajador desplazado, la directiva adopta una serie de medidas para luchar contra el abuso y fraude empresarial y, en concreto, para acabar con los «desplazamientos sucesivos». En este ámbito, el control por las autoridades estatales de los supuestos fraudulentos y el suministro de información suficiente sobre los derechos de los trabajadores son algunas de las cuestiones que los Estados tendrán que sortear y perfilar, si se quiere proteger de forma efectiva al trabajador desplazado.

En suma, debe ser por tanto bien saludada esta nueva estrategia con la que la UE pretende incrementar la protección del trabajador, aunque el éxito de la misma dependerá de su efectiva incorporación en los ordenamientos jurídicos de los diferentes Estados miembros y de cómo se resuelvan los recursos de anulación que Hungría y Polonia han presentado contra la mencionada directiva ante el TJUE. En cualquier caso, estaremos pendientes del correspondiente fallo - esperemos que sea favorable a considerar la protección de los trabajadores como justificación suficiente de la restricción a la libre prestación de servicios, en contra de la postura de los Estados recurrentes o, al menos, ese es nuestro deseo-.

No obstante, aún quedan dos retos fundamentales por alcanzar al legislador europeo. Por una parte, debe proporcionar una regulación adecuada y efectiva a los trabajadores en el ámbito del transporte por carretera. A nuestro juicio, debería proveerse a estos trabajadores de una regulación específica y exclusiva. No resulta admisible, pues, como así pretende la Comisión, adaptar y aplicar a estos trabajadores lo dispuesto en el texto de la Directiva 96/71, en la medida en que son trabajadores que presentan características específicas. Y, por otra, se precisa la creación de un organismo europeo que vele por el cumplimiento efectivo de la normativa laboral y, en particular, la relativa al desplazamiento de trabajadores.

\section{Bibliografía}

Cairós Barret, D. M. (2017). El ámbito objetivo de aplicación de la Directiva 96/71/ CE y la prevención de abusos y elusión de normas. Los desplazamientos realizados a través de empresas de trabajo temporal. En O. Fotinopoulou Basurko (coord.). El desplazamiento de trabajadores en el marco de la Unión Europea: presente y futuro (pp. 121-150). Barcelona: Atelier.

Carballo Piñero, L. (2013). Nota a la Sent. del Tribunal Superior de Justicia de Oviedo, Sala de lo Social, de 1 de febrero de 2013. Revista Española de Derecho Internacional, 2, 326-330. 
Carrascosa González, J. y Rodríguez Piñero-Royo, M. C. (1993). Desplazamientos temporales de trabajadores en la Comunidad Europea y ley aplicable al contrato de trabajo. Relaciones Laborales, 2, 382-407.

Corneloup, S. (2015). Nota a la Sentencia del TJUE de 12 de febrero de 2015. Revue critique de droit international privé, 3, 680-688.

Däubler, W. (1997). Die Entsende-Richtlinie und ihre Umsetzung in das deutsche Recht. Europäische Zeitschrift für Wirtschaftsrecht, 613-618.

Davies P. (1997). Posted Workers: Single Market or Protection of National Labour Law Systems? Common Market Law Review, 751-602.

De Götzen E. (2014). Contratto di lavoro, criteri di collegamento e legge applicabile: luci e ombre del Regolamento (CE) n. 593/2008. Rivista di diritto internazionale privato e processuale, 2014, 3, 540-544.

Eichenhofer, E. (1996). Arbeitsbedingungen bei Entsendung von Arbeitnehmer. Zeitschrift für ausländisches und internationales Arbeits-und Socialrecht, 55-82.

Fotinopoulou Basurko, O. (2015). Panorámica general de la Directiva 2014/67/UE de ejecución de la Directiva sobre desplazamiento de trabajadores en el marco de una prestación de servicios transnacional. Revista de Derecho Social, 70. 123147.

_ (2017). Reflexiones en torno a la noción de habitualidad vs. temporalidad en las normas de Derecho internacional privado del trabajo europeas. En O. Fotinopoulou Basurko (coord.). El desplazamiento de trabajadores en el marco de la Unión Europea: presente y futuro (pp. 249-273). Barcelona: Atelier.

Fotinopoulou Basurko, O. y Larrazabal Astigarra, E. (2015). El salario mínimo aplicable al trabajador desplazado. Revista General de Derecho del Trabajo y de la Seguridad Social, 41, 252-271.

Gárate Castro, J. (2013). Los desplazamientos temporales de trabajadores en el marco de una prestación de servicios. Valencia: Tirant lo Blanch.

Gil Pérez, M. (2017). Repensando el núcleo duro de condiciones de trabajo en el Estado de acogida y la protección de los trabajadores desplazados. En O. Fotinopoulou Basurko (coord.). El desplazamiento de trabajadores en el marco de la Unión Europea: presente y futuro (pp.173-188). Barcelona: Atelier.

Gómez Abelleira, F. J. (2018). Desplazamiento transnacional laboral genuino y ley aplicable al contrato de trabajo. Cuadernos de Derecho Transnacional, 10 (1), 213-232. Disponible en: https://doi.org/10.20318/cdt.2018.4113.

Gómez Muñoz, J. M. (2016). Principios del derecho del trabajo en la jurisprudencia del Tribunal de Justicia de la Unión Europea. XXVII Jornadas Catalanas de Derecho del Trabajo "In memoriam profesor M. R. Alarcón" (pp. 1-42). Disponible en: https:// bit.ly/2IRpQ9l.

Guamán Hernández, A. (2016). La propuesta de reforma de la Directiva 96/71 de desplazamiento de trabajadores en el marco del Plan de Trabajo de la Comisión Europea para el 2016. Revista de Derecho Social, 73, 113-126.

Guichaoua, H. (2014). Une avancée remarquable dans la lutte contre le travail illégal et le dumping social du fait des entreprises étrangères: les arrêts Easy Jet et Vueling. Le Droit Ouvrier, 79, 385-390. 
Gutiérrez-Solar Calvo, B. (2000). El desplazamiento temporal de trabajadores en la Unión Europea. Pamplona: Aranzadi.

Henze, M. (2017). Die Anknüpfung von mobilen Arbeitsverhältnissen anhand des Art. 8 Rom I-Verordnung. Baden Baden: Nomos. Disponible en: https://doi. org/10.5771/9783845282992.

Jault-Seseke, F. (2015). Nota a la Sent. de la Cour de Cassation (Soc.) francesa de 13 de noviembre de 2014. Revue critique de droit international privé, 2, 396-400.

Kramer, A. (2016). Stellungnahme des Deustchen Gewerkschaftsbundes zu Vorschlag für eine Rictlinie zur Änderung der Richtlinie 96/71/EG von 16.Dezember 1996 über die Entsendung von Arbeitnehmern im Rahmen der Erbringung von Dienstleistungen. Deutscher Gewerkschaftsbund, 1-13.

López Rubia, M. E. (2017). El acceso a la información en el marco de las condiciones de empleo y la cooperación administrativa entre los Estados miembros en el contexto del desplazamiento de trabajadores. En O. Fotinopoulou Basurko (coord.). El desplazamiento de trabajadores en el marco de la Unión Europea: presente y futuro (pp. 305-322). Barcelona: Atelier.

Llobera Vila, M. (2017). El desplazamiento temporal de trabajadores y normas de protección del Estado de prestación temporal de servicios. Revista del Ministerio de Empleo y Seguridad Social, 132, 201-203.

_ (2018). La respuesta europea a las «empresas buzón»: normas y jurisprudencia en el ámbito social, tributario y de transporte. Cuadernos de Derecho Transnacional, 10 (2), 536-566.

Mankowski, P. (2009). Employment Contracts under Article 8 of the Rome I Regulation. En F. Ferrari y S. Leible (eds.). Rome I Regulation. The Law Applicable to Contractual Obligations in Europe (pp. 204-207). Munich: Sellier European Law Publishers.

— (2017). Die Unionsrechtskonformität des Mindestlohngesetzes — unter besonderer Berücksichtigung des grenzüberschreitenden Straßenverkehrs Prof. Dr., Hamburg Rechtsgutachten, erstellt im Auftrag des Deutschen Gewerkschaftsbunds und des Bundesverbands Güterkraftverkehr Logistik und Entsorgung (BGL) e.V. 11. April 2017, 1-42.

Marchal Escalona, N. (2002). Algunas reflexiones sobre el régimen jurídico de los desplazamientos transnacionales de trabajadores en la Unión Europea. Revista Española de Derecho Internacional, 54 (2), 811-823.

— (2016). Las cláusulas sociales en los contratos públicos: ¡son contrarias al Derecho de la Unión Europea? Bitácora Millennium DIPr: Derecho Internacional Privado, 3, 1-18.

Martín Belintxon, U. (2016). Dumping social, desarmonización socio-laboral y Derechos internacional privado: la des-Unión Europea. Anuario Español de Derecho Internacional Privado, 16, 611-642.

Martín Hernández, M. L. (2017). Seguimiento del cumplimiento de la Directiva 2014/67/UE y de la Directiva 96/71/CE: el papel de la Inspección de Trabajo”. En O. Fotinopoulou Basurko (coord.). El desplazamiento de trabajadores en el marco de la Unión Europea: presente y futuro (pp. 323-352). Barcelona: Atelier. 
Molina Navarrete, C. (2016). Libertades económicas y norma laboral: Stop «dumping social». Revista de Trabajo y Seguridad Social, 401-402, 5-18.

Monereo Pérez, J. L y Ortega Lozano, P. G. (2018). Sobre unas condiciones laborales equivalentes en la Unión Europea: a propósito de la Directiva (UE) 2018/957 de desplazamiento de trabajadores y la propuesta de Reglamento por la que se crea la Autoridad Laboral Europea. La Ley Unión Europea, 62, 1-14.

Moreau, M. A. (1996). Le détachement des travailleurs effectuant une prestation de services dans l'Union européenne. Journal du droit international, 123 (4), 889-908.

Muller, F. (2014). Cross-Border Mobility of 'Bogus' Self-Employed Workers: A Lack of Legal Framework Coupled with Protection of Economic Rights. European Labour Law Journal, 5, 306-321. Disponible en: https://doi. org/10.1177/201395251400500308.

Nadalet, S. (2008). L'attuazione della Direttiva 96/71 sul distacco. Lavoro e Diritto, $1,37-44$.

Palao Moreno, G. (1997). Directiva 96/71/CE del Parlamento Europeo y del Consejo de 16 de diciembre de 1996 sobre el desplazamiento de trabajadores efectuado en el marco de una prestación de servicios. Revista Española de Derecho Internacional, 49, 1, 377-380.

— (2000). La Ley 45/1999, de 29 de noviembre, sobre el desplazamiento de trabajadores en el marco de una prestación de servicios transnacional: un nuevo paso hacia la consolidación de un mercado de trabajo integrado en Europa. Gaceta Europea, 208, 43-62.

Páramo Montero, P. (2015). La nueva Directiva 2014/67/UE sobre el desplazamiento temporal de trabajadores. Trabajo y Derecho: Nueva Revista de Actualidad y Relaciones Laborales, 3, 52-70.

Pelkmans J. y Correia de Brito, A. (2012). Enforcement in the EU Single Market. CEPS.

Quiñones Escámez A. (2002). Otra lectura de la jurisprudencia del TJCE sobre desplazamiento de trabajadores (del Asunto Arblade al Portugaia). Revista de Derecho Comunitario Europeo, 12, 435-453.

Rebhahn, R. (1999). Entsendung von Arbeitnehmern in der EU-arbeitrechtliche Fragen zum Gemainschaftrecht. Das Recht der Arbeit, 3, 173-179.

Risak, M. (2016). Die Dinge anders angehen? Überlegungen zum Vorschlag der Europäischen Kommission zur Änderung der Entsende-RL 96/71/EG. Das Recht das Arbeit, 5, 1.

Rodière, P. (1998). Détachament et expatriation : Les éléments de la distinction. Droit et pratique du commerce international, 9-18.

Sørensen, K. E. (2015). The fight against letterbox companies in the internal market. Common Market Law Review, 52, 85-118.

Van Hoek, A. y Houwerijl, M. (2011). Comparative on the Legal Aspects of the Posting of Workers in the Framework of the Provision of Services in the European Union (to the Eurpean Commission), March. 
Velázquez Fernández, M. (2017). La transposición (tardía) de la Directiva sobre control de desplazamientos transnacionales en la UE/EEE en el Real Decreto Ley 9/2017 de 26 de mayo. Revista de Trabajo y Seguridad Social, 412, 95-108. 